\title{
Prognosis in patients with suspected or known ischemic heart disease and normal myocardial perfusion: Long-term outcome and temporal risk variations
}

\author{
Jane A. Simonsen, MD, ${ }^{a}$ Oke Gerke, MSc, PhD, ${ }^{\mathrm{a}, \mathrm{b}}$ Charlotte K. Rask, MD, ${ }^{\mathrm{a}}$ \\ Mohammad Tamadoni, MD, a Anders Thomassen, MD, ${ }^{a}$ Søren Hess, MD, ${ }^{a}$ \\ Allan Johansen, MD, DMSc, ${ }^{a}$ Hans Mickley, MD, DMSc, ${ }^{c}$ Lisette O. Jensen, MD, \\ $\mathrm{PhD}, \mathrm{DMSc},{ }^{\mathrm{c}}$ Jesper Hallas, MD, DMSc, ${ }^{\mathrm{d}}$ Werner Vach, MSc, PhD, ${ }^{\mathrm{e}}$ and \\ Poul F. Høilund-Carlsen, MD, DMSc ${ }^{\mathrm{a}}$
}

Background. The prognostic value of a normal myocardial perfusion scintigraphy (MPS) may be well described, but long-term follow-up data are sparse, and temporal variations in risk are insufficiently elucidated.

Methods and Results. During long-term follow-up (mean 6.2 years) of 1,327 consecutive Danish patients with normal MPS, the rate of all-cause death (ACD) was 1.9\%/year (differing by gender) and of cardiac death (CD)/myocardial infarction (MI) $0.8 \% /$ year (differing by coronary artery disease, CAD). Female gender (HR: 0.60), age (HR: 1.07 per-year increment), and known CAD without prior revascularization (HR: 2.17) were statistically significant factors for ACD, whereas diabetes and previous MI per se were not. Known CAD with previous revascularization carried a low risk of $A C D$ when adjusted for gender and age (HR: 0.56). For $\mathrm{CD} / \mathrm{MI}$, risk increased with age and threefold with known CAD, previous MI, and previous percutaneous coronary intervention. Judged from smoothed hazard functions, mortality risk increased further with time for men, elderly, and diabetics and markedly further with known CAD without prior revascularization.

Conclusions. Following a normal MPS, rates of death and hard cardiac events were low. Risk varied with age, gender, and disease history. Novel aspects of temporal risk variation suggested a general warranty period of 5 years, but less in risk groups. ( $J$ Nucl Cardiol 2013;20:347-57.)

Key Words: Myocardial perfusion imaging: SPECT • diagnostic and prognostic application • outcomes research · coronary artery disease

From the Department of Nuclear Medicine, ${ }^{a}$ Department of Cardio$\operatorname{logy},{ }^{\mathrm{c}}$ Odense University Hospital, Odense, Denmark; Centre of

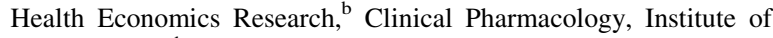
Public Health, ${ }^{\mathrm{d}}$ University of Southern Denmark, Odense, Denmark; and Clinical Epidemiology, Institute of Medical Biometry and Medical Informatics, ${ }^{\mathrm{e}}$ University Medical Center Freiburg, Freiburg, Germany

Werner Vach and Poul F. Høilund-Carlsen shared last authorship.

Grant support: The work was supported by grants from the $\mathrm{PhD}$ Research Fund at Odense University Hospital.

Received for publication Nov 14, 2012; final revision accepted Feb 11, 2013.

Reprint requests: Jane A. Simonsen, MD, Department of Nuclear Medicine, Odense University Hospital, Odense, Denmark; jane.simonsen@ouh.regionsyddanmark.dk.

$1071-3581 / \$ 34.00$

Copyright (c) 2013 American Society of Nuclear Cardiology.

doi:10.1007/s12350-013-9696-0

\section{INTRODUCTION}

A large body of literature exists documenting the short-term prognostic value of myocardial perfusion scintigraphy (MPS). ${ }^{1}$ A systematic review of English language articles addressing the prognostic effectiveness of single photon emission computed tomography (SPECT) MPS in patients with suspected or known coronary artery disease (CAD) was provided by Mowatt et al. ${ }^{2}$ Typically, end points were cardiac death (CD) and non-fatal myocardial infarction (MI), the so-called hard cardiac events. ${ }^{1}$ It is well known that a normal stress MPS implies a good clinical outcome with rates of hard cardiac events and all-cause death (ACD) comparable to those of the general population. ${ }^{3-5}$ Yet, these rates vary from a low of $0.2 \%$ to a high of nearly $2 \%$, reflecting 
differences in underlying clinical risk (age, co-morbidity, etc.) and prior CAD. ${ }^{6-10}$ Especially, during the last decade, there has been a growing recognition of the importance of the underlying burden of atherosclerosis as a primary determinant of prognosis. ${ }^{11}$ Furthermore, ethnic and socioeconomic differences have been pinpointed. ${ }^{12,13}$ Recently, reports on long-term outcome after (normal) MPS have also been emerging. ${ }^{14,15}$

Despite this wealth of information, gaps in our knowledge base do still remain. ${ }^{11,16}$ These knowledge gaps concern long-term outcome, in some cases revealing shifts in risk over time, thus refining our knowledge on prognosis. ${ }^{11}$ Other related issues are post-test patient management and patients' differential needs for retesting. ${ }^{16} \mathrm{We}$ report on the long-term prognosis of patients with normal MPS including differences with respect to gender and co-morbidity and, in addition, new aspects of temporal variations in risk.

\section{METHODS}

\section{Study Design}

We reviewed a consecutive series of MPS performed at our institution during the years 2002-2007 ( $\mathrm{N}=4,850)$. We included patients referred for suspected or known ischemic heart disease and not included in research protocols in which the result was kept blinded to the clinicians. In order to ensure follow-up data availability, only persons from the regional county (the former County of Funen, considered as representative for the entire country) and not referred from private practicing cardiologists were included. In case a patient had more than one examination during the 6-year period, only the first was used. A total of 2,164 patients fulfilled the inclusion criteria (Figure 1), and follow-up was successful in $99.7 \%$ of these. Follow-up data were collected in January 2012 from the national and regional registers. The number of deaths was determined from the Danish Civil Personal Registration System (records on all Danish citizens, living and deceased). ${ }^{17}$ Causes of death were established from the Danish Register of Causes of Death (receiving all death certificates issued in Denmark). ${ }^{18} \mathrm{CD}$ was defined as death from ischemic heart disease, congestive heart failure, or malignant arrhythmia according to the death certificate. MI was noted if patients had been assigned a diagnosis of ST elevation or non-ST elevation MI according to the Danish National Patient Register (records on all in- and outpatient diagnoses in Denmark). ${ }^{18}$ The number of revascularization procedures was taken from the Western Denmark Heart Registry (records on all coronary angiographies and revascularization procedures performed in Western Denmark). ${ }^{19}$ Diabetics were identified as those taking prescribed insulin or oral anti-diabetic drugs according to The Odense Pharmacoepidemiological Database ${ }^{20}$ comprising all prescriptions in the regional county. Mortality rates in agematched Danish citizens were obtained from Statistics Denmark (key authority on Danish statistics). ${ }^{18}$

\section{MPS}

MPS was performed as SPECT with technetium-99m sestamibi (The Isotope Agency, Herlev, Denmark). The protocol varied a little over the years: a standard 2-day reststress; a 2-day stress-rest; or in recent years, a 1-day stress procedure was carried out (in the latter case with addition of a rest scan only in the case of an abnormal stress study). The stress load consisted of a standard maximum exercise test or a pharmacological stress test with adenosine, dipyridamol, or dobutamine. For both rest and stress studies, imaging was started 60 minutes after injection of sestamibi.

SPECT images were obtained on either of the two rotating dual-headed detector gamma cameras fitted with low-energy, high-resolution collimators. Scatter and attenuation correction was not applied. Image acquisition variables were the following: Marconi Axis camera (Marconi Medical Systems, Inc., Ohio, USA): matrix $64 \times 64$ or $128 \times 128$, pixel size 5.0 or $4.7 \mathrm{~mm}$, and 68 or 120 projections (step-and-shoot technique) with 20 seconds per projection over a $360^{\circ}$ or $204^{\circ}$ anatomical orbit. Picker PRISM 2000 XP (Picker International, Inc., Ohio, USA): matrix $64 \times 64$ or $128 \times 128$, pixel size 5.0 or $4.7 \mathrm{~mm}$, and 60 projections (step-and-shoot technique) with 20 seconds per projection over a $180^{\circ}$ or $360^{\circ}$ elliptical orbit. Datasets were reconstructed by iterative reconstruction (OSEM) and post-filtered using a three-dimensional Butterworth filter (order, 2.5; cut-off, gated data, 0.21, ungated data, 0.37).

All scans were interpreted visually and semi-quantitatively using ungated short-axis, horizontal and vertical longaxis myocardial tomograms. Initially, we used non-gated acquisitions and bull's eye displays, and a normal scan was defined as a study with normal radionuclide distribution throughout the myocardium. Later, gated studies were used with left ventricular ejection fraction (LVEF) being available in 960 of the patients. In 1,313 of the cases, a summed stress score (SSS) was obtained using the AutoQuant ${ }^{\circledR}$ software, and a 20-segment model with 5-point grading: $0=$ normal; 1 = equivocal; $2=$ moderate; $3=$ severe; or $4=$ the complete absence of visible radioactivity in a segment. A normal scan was defined as one with an SSS of less than 4 and no segments with a stress score of 2 or greater. ${ }^{21}$

\section{Statistics}

The primary end point was ACD, whereas composite end points like (i) ACD or MI; (ii) CD or MI; and (iii) ACD, MI, or coronary revascularization procedure were investigated as exploratory secondary end points. For the latter, we only included revascularization procedures performed $>180$ days after MPS to cover new events, because revascularization before then was considered driven by MPS results or based on an indication established before MPS. For examination of the rates of (cardiac) death and MI, patients were not censored in case of revascularization before the event of interest. For composite end points, only the time until the first event was considered. Follow-up began on the date of the MPS and continued until the date of the respective event, relocation, or end of follow-up period (December 31, 2011, for CD; 


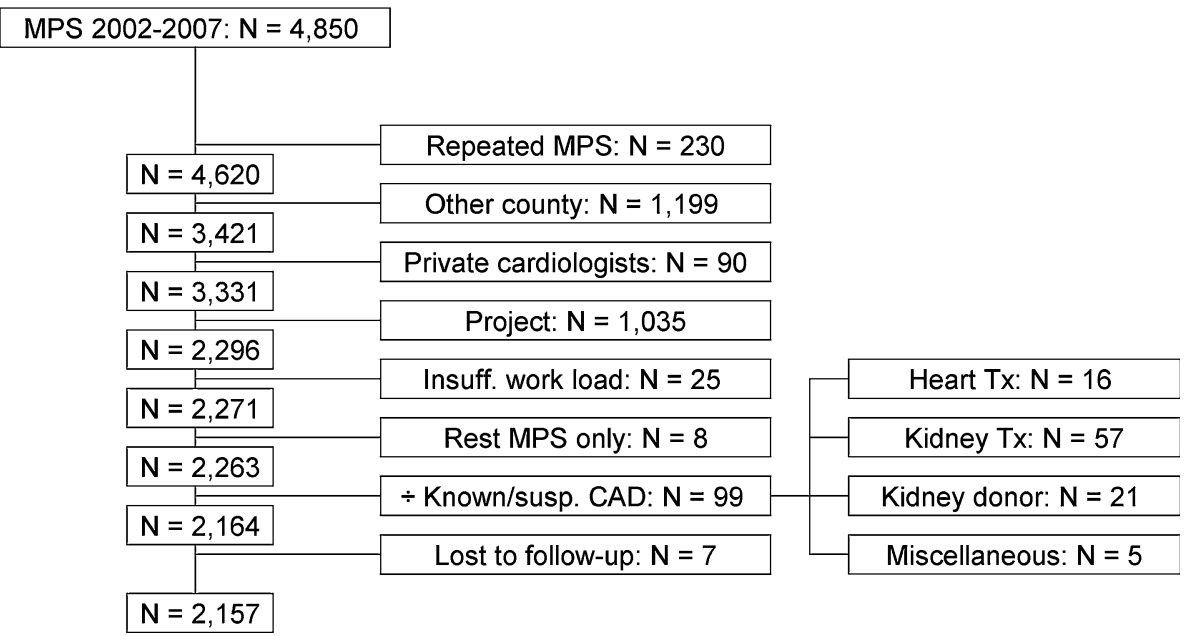

Figure 1. Outline of patient selection MPS, Myocardial perfusion scintigraphy; Susp., suspected; $C A D$, coronary artery disease; $T x$, transplantation.

December 31, 2010 due to delay in registration of causes of death), whichever happened first.

Results are presented as percentages for categorical variables and descriptive statistics like mean (range) or mean \pm standard error of the mean (SEM) for continuous variables. Incidence rates are reported. Differences in frequency distribution were compared by Fisher's exact test or the chi-squared test. Intergroup differences in continuous variables were tested by the unpaired Student's $t$ test. Multiple incidence rate comparisons were done according to Boyd and Radson. ${ }^{22}$ Kaplan-Meier plots and log-rank tests were used in survival analyses. Cox proportional hazards modeling was used to describe the influence of covariates by calculation of both unadjusted and adjusted hazard ratios. Adjustment was performed for the most important confounders. Smoothed hazards functions were used for estimation of mortality rates depending on time. The significance level was set to $5 \%$. Statistical analyses were performed using STATA/MP 12 (@) StataCorp LP, Texas, USA).

\section{RESULTS}

MPS was normal in 1,327 out of 2,157 eligible patients (62\%). Demographic data are shown in Table 1. For those with a normal scan (43\% male), mean age was 59.5 (15.5-88.5) years- $80 \%$ were aged between 44 and 75 years. Diabetes mellitus (DM) was equally present in men and women: $17 \%(95 / 574)$ vs $14 \%$ (107/753), respectively, $P=.25$. Nineteen percent had known CAD, but in women it was only $12 \%$ (89/753) compared to $28 \%(159 / 574)$ in men, $P<.0001$. Of diabetic patients, 26\% (53/202) had known CAD vs 17\% (195/ $1,125)$ of non-diabetics, $P=.004$.

Mean follow-up was $6.2(0.02-9.96)$ years; total follow-up was 8,231 person-years. Table 2 shows the cumulative numbers of events during the follow-up period. Of patients with normal MPS, $81 \%$ were eventfree survivors. Three percent experienced a non-fatal MI while $12 \%$ died. Specific causes of death were ascertained in 133 of the 157 deaths $(85 \%)$. Of these, $10 \%$ were classified as CDs and 90\% as non-cardiac. Late revascularization (percutaneous coronary intervention (PCI) or coronary artery bypass graft surgery $(\mathrm{CABG})>180$ days following MPS) was done in $7 \%$. For all types of events, the cumulative percentages were higher for men than for women, for diabetic vs nondiabetic patients, and for patients with known CAD compared to those with suspected CAD.

For ACD, median time to event was 3.9 (0.02-9.4) years. Incidence rates were, in terms of ACD: $1.9 \%$ / year; ACD or MI: $2.4 \% /$ year; CD or MI: $0.8 \% / y e a r ;$ and $\mathrm{ACD}, \mathrm{MI}$, or late coronary revascularization: $3.2 \%$ year. All-cause mortality rates differed according to gender (men: $2.5 \%$ year; women: $1.5 \% /$ year, $P=.002$ ), while no differences were found in the subsets $+/-\mathrm{DM}$ or $+/-\mathrm{CAD}$. Cardiac event rates differed only by CAD; for $\mathrm{CD}$ or $\mathrm{MI}$ incidence rates were $1.8 \%$ vs $0.6 \%$ per year $(P=.0001)$ with vs without a history of CAD. Incidence rates according to age are shown in Table 3. The cardiac event rate exceeded $1 \%$ per year only in the group of patients $\geq 85$ years old. The all-cause mortality rate was $1.5 \%$ /year for patients $<75$ years old and $6.0 \% / y e a r$ for patients $\geq 75$ years old, $P<.00001$.

Kaplan-Meier survival estimates were calculated for all end points. Those for ACD and the composite end point of death, MI, or late revascularization are depicted in Figure 2. With respect to gender, the differences were apparent for all end points (Figure 2A). The group of diabetics was small, and the curves did not differ 
Table 1. Demographic data

\begin{tabular}{|c|c|c|c|}
\hline & All $(N=2,157)$ & $\begin{array}{c}\text { Normal MPS } \\
(\mathbf{N}=1,327)\end{array}$ & $\begin{array}{c}\text { Abnormal MPS } \\
(\mathbf{N}=\mathbf{8 3 0})\end{array}$ \\
\hline Males & $1,152(53 \%)$ & $574(43 \%)$ & $578(70 \%)$ \\
\hline Age \pm SEM (years) & $60.9 \pm 0.2$ & $59.5 \pm 0.3$ & $63.1 \pm 0.4$ \\
\hline Known CAD & $720(33 \%)$ & 248 (19\%) & $472(57 \%)$ \\
\hline Previous MI & $394(18 \%)$ & $87(7 \%)$ & 307 (37\%) \\
\hline Previous $\mathrm{PCI}$ & $400(19 \%)$ & $149(11 \%)$ & $251(30 \%)$ \\
\hline Previous CABG & $219(10 \%)$ & $59(5 \%)$ & $160(19 \%)$ \\
\hline Medically treated DM & 407 (19\%) & $202(15 \%)$ & $205(25 \%)$ \\
\hline Exercise stress test & $453(21 \%)$ & $369(28 \%)$ & $84(10 \%)$ \\
\hline Adenosine & $1,565(73 \%)$ & $865(65 \%)$ & $700(84 \%)$ \\
\hline Dobutamine & $126(6 \%)$ & $86(7 \%)$ & $40(5 \%)$ \\
\hline Dipyridamol & $13(0.6 \%)$ & $7(0.5 \%)$ & $6(0.7 \%)$ \\
\hline Use of acetyl salicylic acid & $1,468(68 \%)$ & 797 (60\%) & $671(81 \%)$ \\
\hline Use of $\beta / \alpha$ blocker & $930(43 \%)$ & $462(35 \%)$ & $468(56 \%)$ \\
\hline Use of calcium channel blocker & $558(26 \%)$ & $325(24 \%)$ & $233(28 \%)$ \\
\hline Use of nitrates & $497(23 \%)$ & $279(21 \%)$ & $218(26 \%)$ \\
\hline Use of lipid-lowering agents & $988(46 \%)$ & $481(36 \%)$ & $507(61 \%)$ \\
\hline Hypertension $(\mathrm{N}=1,046)$ & $537(51 \%)$ & $218(53 \%)$ & $319(50 \%)$ \\
\hline \multicolumn{4}{|l|}{ Smoking $(\mathrm{N}=925)$} \\
\hline Current & $260(28 \%)$ & $98(26 \%)$ & $162(29 \%)$ \\
\hline Never & $282(30 \%)$ & $136(37 \%)$ & $146(26 \%)$ \\
\hline Ceased & $383(41 \%)$ & $137(37 \%)$ & $246(44 \%)$ \\
\hline $\begin{array}{l}\text { Family history of CAD } \\
\qquad(\mathrm{N}=1,017)\end{array}$ & $475(47 \%)$ & $203(51 \%)$ & $272(44 \%)$ \\
\hline SSS \pm SEM & $5.6 \pm 0.2(\mathrm{~N}=1,313)$ & $2.0 \pm 0.1(\mathrm{~N}=814)$ & $11.4 \pm 0.4(\mathrm{~N}=499)$ \\
\hline Stress LVEF \pm SEM (\%) & $57.4 \pm 0.4(\mathrm{~N}=895)$ & $62.6 \pm 0.4(\mathrm{~N}=536)$ & $49.6 \pm 0.7(\mathrm{~N}=359)$ \\
\hline Rest LVEF \pm SEM (\%) & $58.2 \pm 0.5(\mathrm{~N}=906)$ & $63.9 \pm 0.4(\mathrm{~N}=494)$ & $51.4 \pm 0.7(\mathrm{~N}=412)$ \\
\hline
\end{tabular}

MPS, myocardial perfusion scintigraphy; SEM, standard error of the mean; $C A D$, coronary artery disease; $M I$, myocardial infarction; $P C I$, percutaneous coronary intervention; $C A B G$, coronary artery bypass graft surgery; $D M$, diabetes mellitus; SSS, summed stress score; $L V E F$, left ventricular ejection fraction.

significantly with regard to death or death/MI, but when late revascularization was also taken into account, diabetics had significantly more events than non-diabetic patients (Figure 2B). For patients with known CAD, no differences were observed in mortality rates, but regarding the composite end points, the difference was distinct and more so when late revascularization was included (Figure 2C).

Results of a Cox proportional hazards analysis are shown in Table 4. In univariate models, female gender (HR: 0.60), age (HR: 1.07 per one year's increment), and known CAD without previous PCI/CABG (HR: 2.17) were statistically significant factors for the primary end point, whereas the effects of DM, known CAD with previous revascularization, and previous MI were nonsignificant. Women with normal MPS were a little older than men with normal scans $(60.2 \pm 0.4$ vs $58.6 \pm$ 0.5 years, $P=.02$ ), and after adjustment for age, the gender difference in mortality rates was even more marked. The effect of gender persisted when adjusted for DM or CAD. The effect of known CAD with no previous revascularization became insignificant when adjusted for gender and age, whereas known CAD with previous revascularization carried a lower risk for ACD when adjusted for gender and age. For CD or MI, risk increased with age and threefold with known CAD, previous MI, and previous PCI.

Smoothed hazard functions (the estimated risk of ACD at every time point) are outlined in Figure 3. For the whole population with normal MPS, there was a very low risk in the beginning, increasing slowly during the first $3 \frac{1}{2}$ years to reach a plateau, not surpassing $2 \%$ in the first 5 years. Except from the outset, risk - albeit low-was higher than in the age-matched general population (Figure 3A). The risk of women increased more smoothly during the whole period and surpassed $2 \%$ after 7 years (Figure 3B). For 


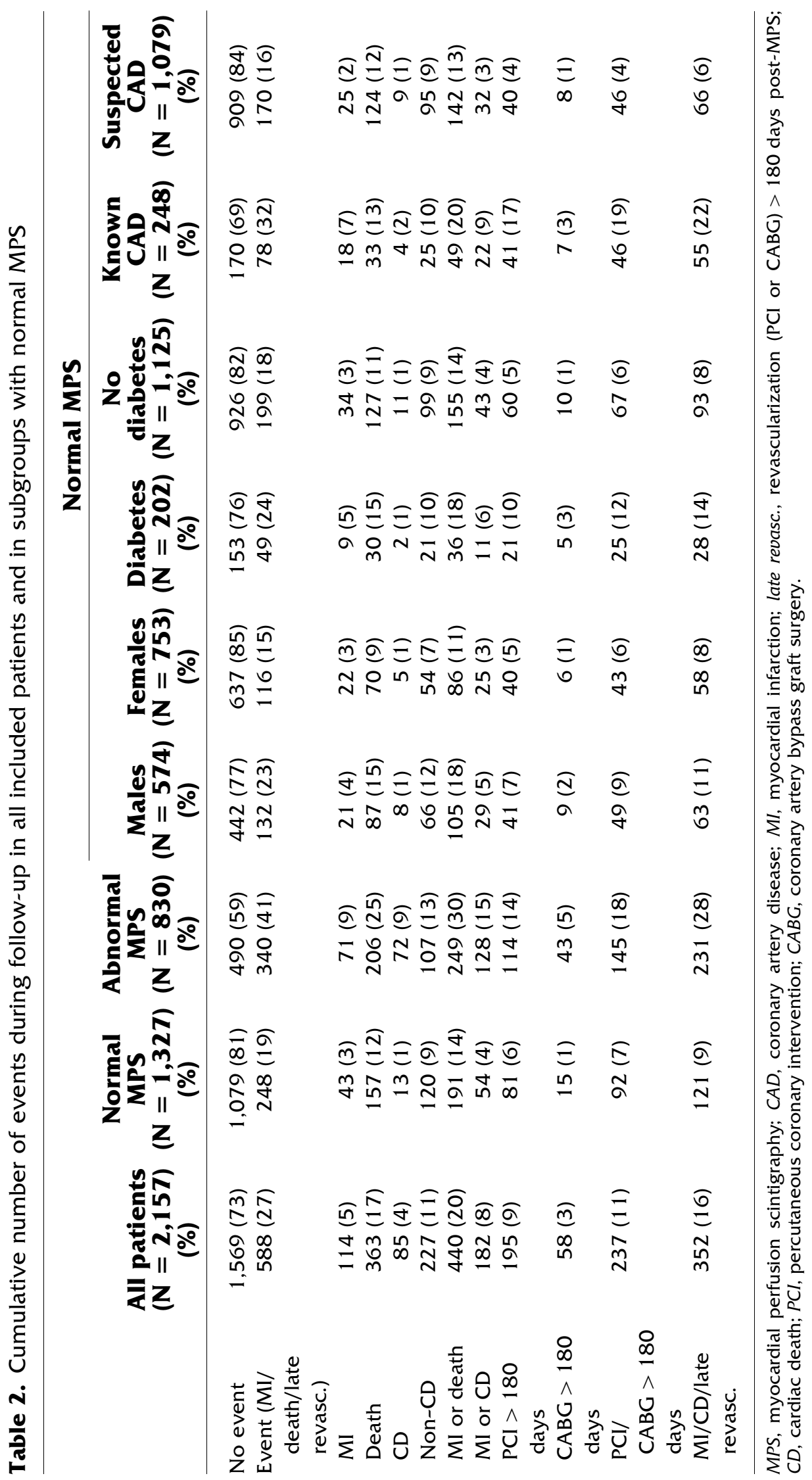


Table 3. Mortality rates according to age

\begin{tabular}{lccccc}
\hline $\begin{array}{c}\text { Age } \\
\text { (years) }\end{array}$ & $\begin{array}{c}\text { Number of } \\
\text { subjects }\end{array}$ & $\begin{array}{c}\text { Mortality rate } \\
\text { (\% per year) }\end{array}$ & $\begin{array}{c}\text { Time at risk } \\
\text { (years) for ACD }\end{array}$ & $\begin{array}{c}\text { Cardiac mortality } \\
\text { rate (\% per year) }\end{array}$ & $\begin{array}{c}\text { Time at risk } \\
\text { (years) for CD }\end{array}$ \\
\hline $15-24$ & 8 & 2.1 & 47 & 0 & 40 \\
$25-34$ & 23 & 0.6 & 170 & 0.7 & 148 \\
$35-44$ & 116 & 0.4 & 758 & 0.2 & 652 \\
$45-54$ & 294 & 0.7 & 1,923 & 0 & 1,646 \\
$55-64$ & 459 & 1.7 & 2,866 & 0 & 2,464 \\
$65-74$ & 288 & 2.6 & 1,728 & 0.2 & 1,482 \\
$75-84$ & 131 & 5.8 & 701 & 1.0 & 611 \\
$85-94$ & 8 & 7.9 & 38 & 6.0 & 33 \\
\hline
\end{tabular}

$A C D$, all-cause death; $C D$, cardiac death.

patients aged $\geq 75$ years the increase was steep with risk being $2 \%$ in the beginning but $>10 \%$ in 7 years (Figure 3C). Diabetics and non-diabetics shared risk for the first 3 years, whereupon the risk of diabetics rose steadily over 4 years (Figure 3D). For patients with merely the suspicion of CAD the risk was below $2 \%$ for the first 4 years. The risk of patients with known CAD and a history of revascularization $(\mathrm{N}=194,15 \%$ of all $)$ had a small initial top but stabilized at a lower level after five years. The group with known $\mathrm{CAD}$ and no previous revascularization ( $\mathrm{N}=54,4 \%$ of the patients) had the highest and fastest growing risk, reaching $6 \%$ in 4 years. All deaths in this group occurred within 5 years from MPS (Figure 3E). Including $\mathrm{MI}$ into the definition (i.e., known $\mathrm{CAD}$ with prior revascularization or MI $(\mathrm{N}=216,16 \%$ of all $)$ vs known CAD with no prior revascularization or MI $(\mathrm{N}=32,2 \%$ of all) ) gave the same picture; only the peak risk with no history of revascularization/MI was even higher (7\%) and maximum time-to-event shortened to 4.2 years (Figure $3 \mathrm{~F}$ ).

\section{DISCUSSION}

In this study of patients with definite or suspected CAD, $62 \%$ of MPS were normal, indicating no significant coronary artery lesion causing ischemia, quite in line with earlier observations. ${ }^{23,24}$ Patients with normal MPS generally had a favorable long-term prognosis with respect to ACD (1.9\%/year) and hard cardiac events (0.8\%/year), comparable with previous findings from Europe and the US. However, the risk was higher than that of the general population, which is consistent with the findings of Schinkel et al. ${ }^{15}$ Events occurred relatively late, as previously reported from our institution in a study of similar patients, in which, however, a smaller sample size prevented proper estimation of the relative influence of the underlying risk factors. ${ }^{25}$ The present study had the power to demonstrate that risk varied according to gender, age, and $\mathrm{CAD}$ and that in some subgroups risk changed dramatically over time.

\section{Gender and Age}

Men had a lower frequency of normal scans, consistent with previous findings. ${ }^{26}$ Men with normal MPS had significantly more events than women. Indeed, their risk equated that of diabetic patients, whereas women had a risk similar to non-diabetic patients. A low risk of death and cardiac events in women with normal MPS has previously been reported, ${ }^{6,12}$ even in women with a high pre-test likelihood of disease. ${ }^{27}$ However, others described that in the presence of $\mathrm{DM}$ or CAD women had prognoses equally severe to that of men. ${ }^{28-30}$ In a report by Hachamovitch et al, event rates were greater in diabetic vs non-diabetic women, although no such difference was present in men, and with known CAD, female diabetics had event rates similar to male diabetics and non-diabetics, whereas nondiabetic women had lower event rates. ${ }^{8}$ We found no interaction between gender and DM or CAD.

As expected, in Cox modeling of hazards age was a predictor of both ACD and hard cardiac events, and event rates in the elderly were well beyond $2 \%$ per year. All-cause mortality rates and CD rates for patients aged $75-84$ years and aged $\geq 85$ years were in line with those reported by Hachamovitch et al. ${ }^{31}$

\section{Diabetes Mellitus}

In contrast to a recent update stating markedly higher annual death rates in diabetic patients even with normal MPS, ${ }^{1}$ DM itself was not a significant predictor of ACD or $\mathrm{CD} / \mathrm{MI}$ in our sample. Giri et $\mathrm{al}^{30}$ observed a lower unadjusted cardiac survival rate in diabetics than nondiabetics, which, however, became comparable once adjusted for the pre-test clinical risk and stress MPS results. Likewise, others concluded that the increased risk 
(a)

Death

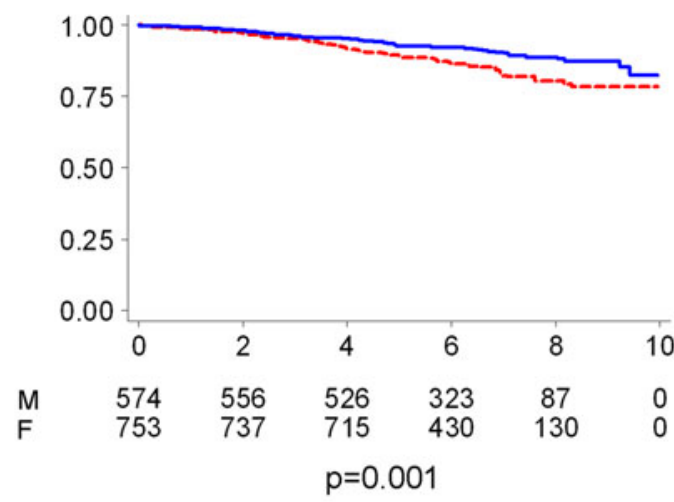

(b)

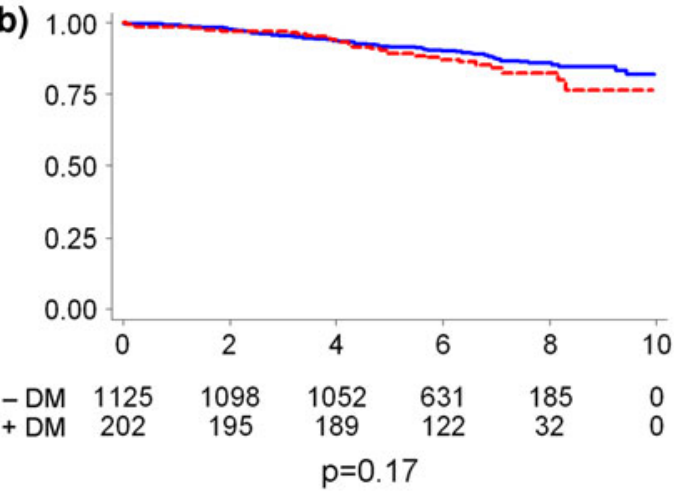

(c)

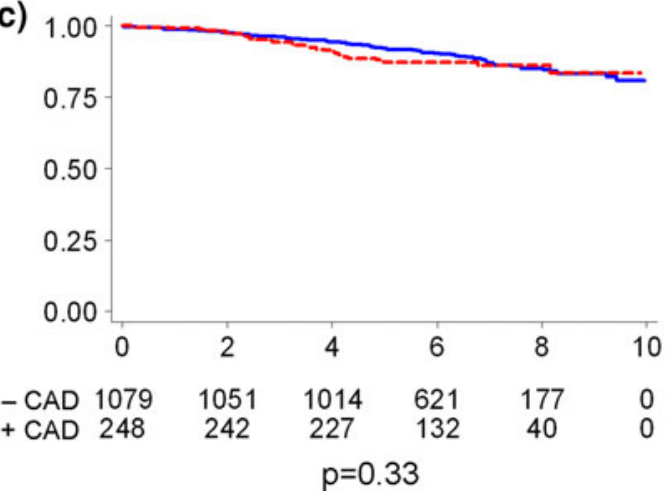

Death, $\mathrm{MI}$, or late revascularization
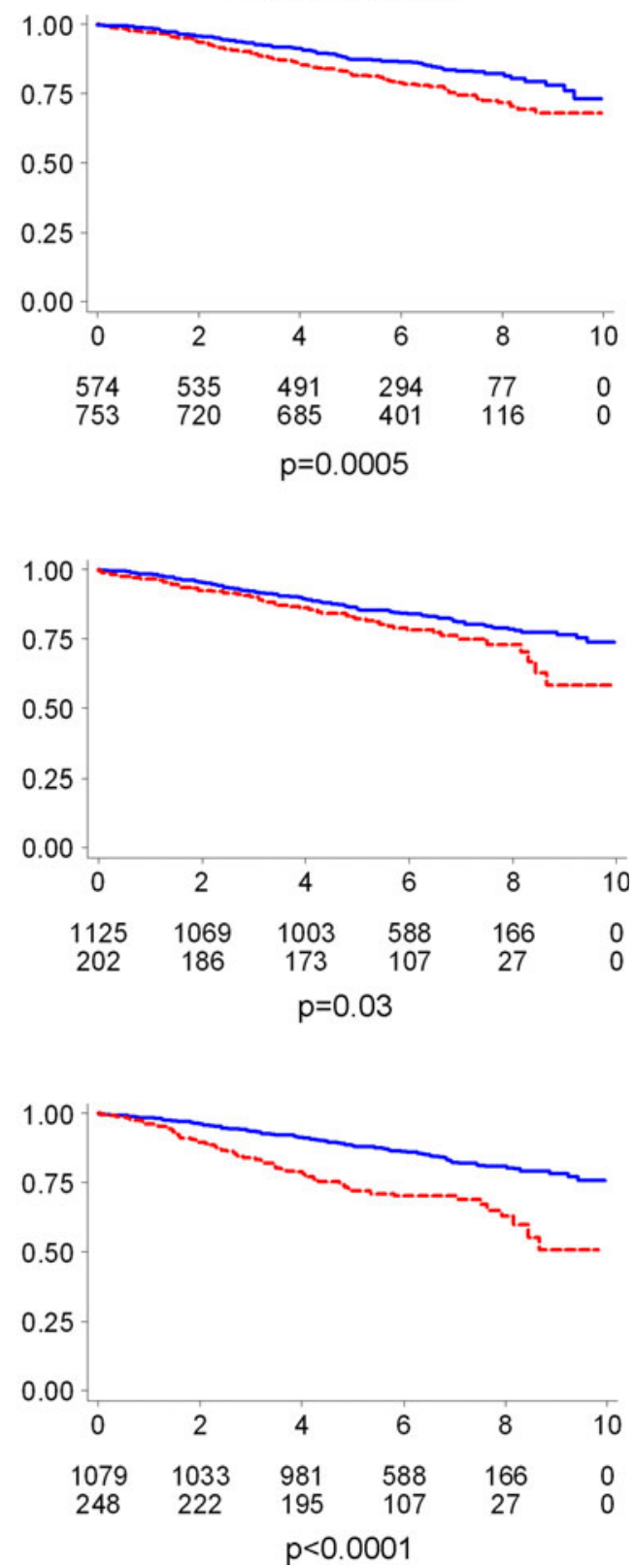

Figure 2. Kaplan-Meier survival estimates of (left column) death and (right column) death, MI, or late revascularization for (A) men (dashed red line) vs women (solid blue line), (B) diabetics (dashed red line) vs non-diabetics (solid blue line), and (C) known CAD (dashed red line) vs suspected CAD (solid blue line). Abscissa analysis time (years), ordinate survival probability, below curves number of patients at risk.

of diabetic patients was the result of a high prevalence of $\mathrm{CAD}$ and other risk factors. ${ }^{10,27}$

\section{Coronary Artery Disease}

The lower prevalence of known CAD in women referred for stress MPS was in the same order of magnitude as reported by Zafrir et $\mathrm{al}^{28}$ while in other studies, there was only a small gender difference. ${ }^{8}$ Cardiac event rates differed by $+/-$ CAD to a similar extent as shown by others. ${ }^{8,9}$ As expected and also in line with previous findings, ${ }^{9} \mathrm{CAD}$ was a stronger predictor of hard cardiac events than of ACD. Thus, even with a normal MPS, risk appears 
Table 4. Cox proportional hazards regression models

\begin{tabular}{|c|c|c|c|c|c|c|}
\hline & \multicolumn{3}{|c|}{ ACD } & \multicolumn{3}{|c|}{ CD or MI } \\
\hline & Hazard ratio & CI & $P$ value & Hazard ratio & CI & $P$ value \\
\hline \multicolumn{7}{|l|}{ Gender (women vs men) } \\
\hline Univariate analysis & 0.60 & {$[0.44,0.82]$} & .001 & 0.67 & {$[0.39,1.15]$} & .15 \\
\hline Adjusted for age & 0.51 & {$[0.37,0.71]$} & $<.0001$ & 0.60 & {$[0.35,1.03]$} & .07 \\
\hline Adjusted for DM & 0.60 & {$[0.44,0.83]$} & .002 & 0.67 & {$[0.39,1.16]$} & .15 \\
\hline Adjusted for known CAD & 0.61 & {$[0.44,0.84]$} & .002 & 0.82 & {$[0.47,1.42]$} & .48 \\
\hline \multicolumn{7}{|l|}{ Age (one year's increase) } \\
\hline Univariate analysis & 1.07 & {$[1.06,1.09]$} & $<.0001$ & 1.06 & {$[1.03,1.09]$} & $<.0001$ \\
\hline Adjusted for gender & 1.08 & {$[1.06,1.09]$} & $<.0001$ & 1.06 & {$[1.03,1.09]$} & $<.0001$ \\
\hline \multicolumn{7}{|l|}{$\mathrm{DM}$} \\
\hline Univariate analysis & 1.32 & {$[0.89,1.97]$} & .17 & 1.30 & {$[0.65,2.59]$} & .46 \\
\hline Adjusted for gender and age & 1.13 & {$[0.76,1.69]$} & .54 & 1.14 & {$[0.57,2.28]$} & .71 \\
\hline Adjusted for known CAD & 1.30 & {$[0.87,1.94]$} & .20 & 1.14 & {$[0.57,2.27]$} & .72 \\
\hline \multicolumn{7}{|l|}{ Known CAD } \\
\hline Univariate analysis & 1.21 & {$[0.82,1.78]$} & .33 & 2.98 & {$[1.72,5.17]$} & $<.0001$ \\
\hline Adjusted for gender and age & 0.75 & {$[0.50,1.11]$} & .15 & 2.20 & {$[1.23,3.92]$} & .01 \\
\hline Adjusted for DM & 1.18 & {$[0.80,1.74]$} & .40 & 2.95 & {$[1.70,5.14]$} & $<.0001$ \\
\hline \multicolumn{7}{|c|}{ Known CAD with no previous PCI/CABG vs no CAD known } \\
\hline Univariate analysis & 2.17 & {$[1.20,3.92]$} & .01 & 3.43 & {$[1.34,8.82]$} & .01 \\
\hline Adjusted for gender and age & 1.68 & {$[0.92,3.06]$} & .09 & 2.87 & {$[1.11,7.44]$} & .03 \\
\hline Adjusted for DM & 2.13 & {$[1.18,3.86]$} & .01 & 3.41 & {$[1.32,8.76]$} & .01 \\
\hline \multicolumn{7}{|c|}{ Known CAD with previous PCI/CABG vs no CAD known } \\
\hline Univariate analysis & 0.97 & {$[0.61,1.53]$} & .88 & 2.87 & {$[1.57,5.22]$} & .001 \\
\hline Adjusted for gender and age & 0.56 & {$[0.35,0.90]$} & .02 & 2.04 & {$[1.09,3.82]$} & .03 \\
\hline Adjusted for DM & 0.94 & {$[0.59,1.50]$} & .80 & 2.83 & {$[1.55,5.18]$} & .001 \\
\hline \multicolumn{7}{|l|}{ Previous MI } \\
\hline Univariate analysis & 1.05 & {$[0.55,1.99]$} & .89 & 3.66 & {$[1.83,7.29]$} & $<.0001$ \\
\hline Adjusted for gender and age & 0.81 & {$[0.43,1.55]$} & .53 & 3.06 & {$[1.53,6.13]$} & .002 \\
\hline \multicolumn{7}{|l|}{ Previous $\mathrm{PCl}$} \\
\hline Univariate analysis & 0.81 & {$[0,47,1.41]$} & .46 & 2.73 & {$[1.46,5.10]$} & .002 \\
\hline Adjusted for gender and age & 0.52 & {$[0.30,0.91]$} & .02 & 2.02 & {$[1.06,3.84]$} & .03 \\
\hline \multicolumn{7}{|l|}{ Previous CABG } \\
\hline Univariate analysis & 1.05 & {$[0.52,2.14]$} & .89 & 2.06 & {$[0.82,5.18]$} & .13 \\
\hline Adjusted for gender and age & 0.56 & {$[0.27,1.16]$} & .12 & 1.27 & {$[0.49,3.27]$} & .62 \\
\hline
\end{tabular}

Adjusted hazard ratios refer to models with two or three covariates: The covariate of interest, for which the effect is reported, and the covariate(s) adjusted for.

$M I$, myocardial infarction; $C I, 95 \%$ confidence interval; $D M$, diabetes mellitus; $C A D$, coronary artery disease; $P C I$, percutaneous coronary intervention; $C A B G$, coronary artery bypass graft surgery; $A C D$, all-cause death; $C D$, cardiac death.

to be more differentiated than recognized in previous times. $^{32}$

\section{Time Warranty}

Compared with the continuously low mortality risk in the general population, the risk of patients with normal MPS was lower immediately after scintigraphy, increasing for the first $3 \frac{1}{2}$ years but then stabilizing at a $2 \%$ level maintained within 5 years. This may suggest a general warranty period following a normal MPS of 5 years. The risk of diabetics stood out from that of non-diabetics after 3 years (Figure 3D) favoring the argument to retest diabetic patients with normal studies earlier than non-diabetic ones in case of clinical symptom worsening. ${ }^{30}$ The risk of the elderly diverged from that of the younger patients early on and to an increasing extent (Figure 3C). Similarly, a model for prediction of time to hard events in patients with no previous CAD and normal MPS proposed by Hachamovitch et al ${ }^{8}$ included a nonlinear term for age. 
(a)

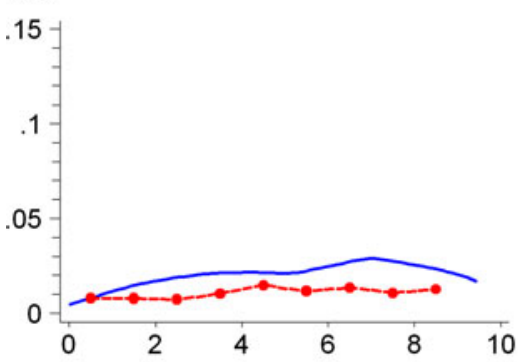

(d)

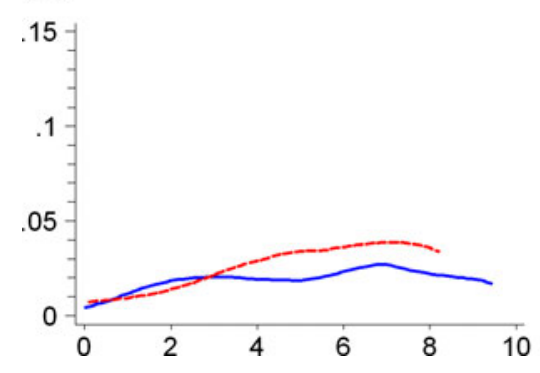

(b)

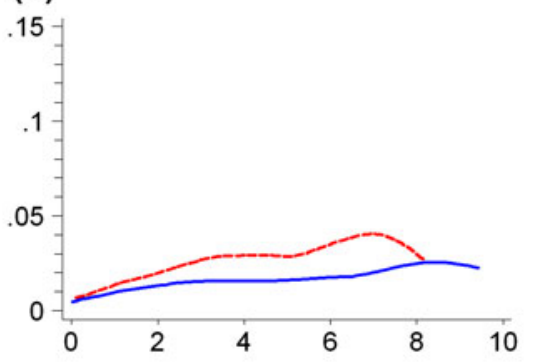

(e)

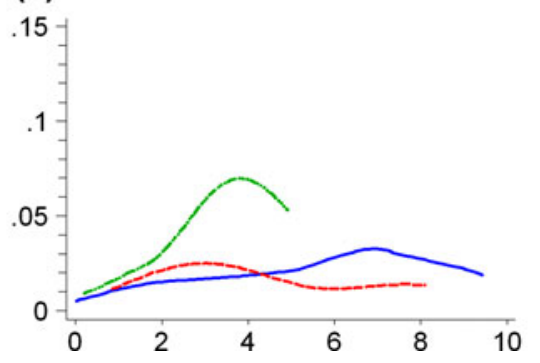

(c)

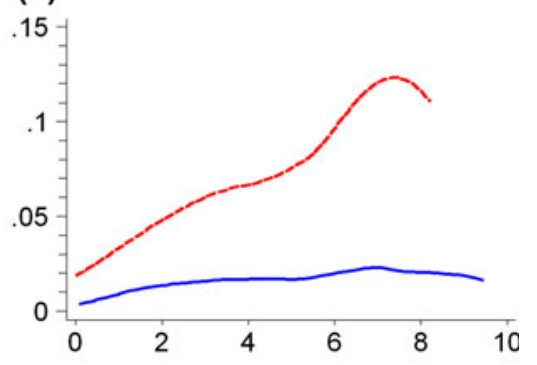

(f)

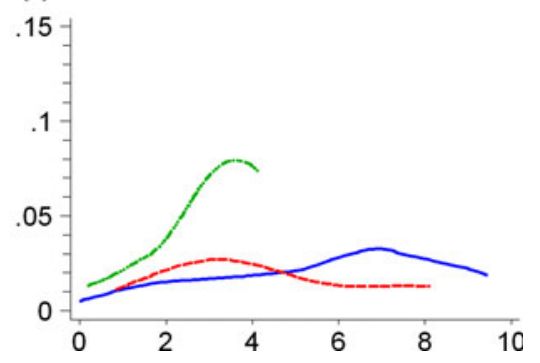

Figure 3. Smoothed hazard functions for ACD. (A) Solid blue line the whole population with normal MPS. Dashed red line with dots the age-matched general population. (B) Gender. Solid blue line women. Dashed red line men. (C) Age. Solid blue line patients $<75$ years. Dashed red line Patients $\geq 75$ years. (D) DM. Solid blue line non-diabetics. Dashed red line diabetics. (E) CAD. Solid blue line no known CAD. Dashed red line: known CAD, history of revascularization. Dashdotted green line known CAD, no history of revascularization. (F) CAD. Solid blue line no known CAD. Dashed red line known CAD, history of revascularization or MI. Dash-dotted green line known CAD, no history of revascularization or MI. Abscissa analysis time (years), ordinate annual mortality rate.

For patients with known CAD, risk changed over time, as was also described in the past. ${ }^{8,9}$ Yet, further stratification showed that after the first few years risk increased rapidly in a small group of patients with CAD without previous revascularization (Figure 3E, F). One possible explanation could be that revascularization, although indicated, was abandoned in patients with a higher co-morbidity. In any case, such method of stratification is new since traditionally only two categories $(+/-\mathrm{CAD})$ were considered. Hachamovitch et al found differentiated survival for patients with no prior $\mathrm{CAD}$, prior revascularization, but no prior MI, and prior MI in a recent article on the impact of ischemia and scar on the therapeutic benefit from myocardial revascularization (45\% of MPS abnormal). ${ }^{33}$ To our knowledge, such stratification was never made in patients with normal MPS, and our finding of a risk up to 6-7\% in spite of a normal MPS for patients with known CAD with no prior revascularization is notable, since these numbers are somewhat higher than those usually reckoned. Therefore, our data indicate that follow-up should be closer in patients with existing CAD or higher risk equivalents like diabetes or old age-quite in agreement with prior proposals. ${ }^{8-10,15,31,34,35}$
A scientific basis for timing of repeat testing has been sought after. In the cases of alterations in the patient's symptoms or functional capabilities, re-testing may be considered when risk begins to accelerate. ${ }^{11}$ Compared with the study of Hachamovitch et $\mathrm{al}^{8}$ discussing the existence of a warranty period from their 2-year follow-up of $>7,000$ patients with normal MPS, our follow-up period was appreciably longer ( $>6$ years), and the most dramatic increases in risk did not occur until after the first two years. In contrast to the reporting of averaged annualized event rates or event rates in circumscribed time intervals after the index study, we used smoothed hazard functions. The strength of these curves is the reflection of the risk at every time point, yielding an opportunity to read tendencies, time points of transboundary risk, and differences between subgroups. Carryer et al tested the timing and type of follow-up studies compared with the warranty periods calculated from Hachamovitch's data. ${ }^{36}$ They found that in patients without prior CAD, follow-up MPS was generally performed well before the end of the warranty period, whereas in patients with known CAD (for whom the warranty period was much shorter), they were on average performed after the expiry of the warranty 
period. However, as stated in a related editorial, rather than a measure of the time to a certain risk of hard events, what is really needed is a measure of the time to develop an abnormal MPS that would allow for an intervention of prognostic benefit to the patient. ${ }^{37}$

\section{Advantages and Limitations}

Large-scale studies on long-term prognosis with normal MPS are still sparse, and such Scandinavian data do not exist. ${ }^{25,38}$ In the European context, reported followup periods were 10,11 , and 15 years, respectively, in only 47, 294, and 233 patients with normal MPS, ${ }^{14,15,35}$ However, in small, low-risk populations a consequently low overall event rate precludes differentiation of risk. ${ }^{39}$ The strengths of the present study are the large population, the completeness of follow-up, and a follow-up period sufficiently long to allow for the prognostic importance of underlying risk factors to become unmasked with the opportunity of bringing new aspects to changes in risk over time. In Denmark, owing to national and regional recordings of all diagnoses, prescriptions, and deaths, the possibilities to identify and follow large patient subsets for a long time are very favorable.

Methodological problems in the prognostic literature pointed out by Dr Hachamovitch ${ }^{16}$ were addressed since we did not censor patients in case of early revascularization leading to removal of high-risk patients, and we used ACD as the primary end point. We did this because of the delay in registration of causes of death in addition to the well-described difficulties encountered in determining the actual cause of death, not to mention the association of CAD with other co-morbid conditions known to be factors independently predictive of death. ${ }^{9,40}$ However, since in our low-risk population only $10 \%$ of deaths were cardiac, predictors of CD could be masked, and we, therefore, also modeled the risk of hard cardiac events.

Inclusion of late revascularization in a composite end point added to the understanding of the prognosis, since late revascularization could be a proxy for a change in clinical status (e.g., new anginal symptoms) that might signify a shortening of the post-normal MPS low risk warranty.

As measurements of LVEF were not available in all patients because of early technical limitations we did not risk stratify according to this variable. Patients were not formally tested for the presence of DM, and hence the " "non-diabetic', group may have contained undiagnosed diabetics and patients with non-pharmacologically treated DM that may have diluted some of our results. With regard to previous findings of a higher mortality rate among the pharmacologically challenged patients ${ }^{7,8,41,42}$ we could not deduce information from the type of stress performed, since in recent times, we for practical reasons chose to use pharmacological stress independently of the estimated work capacity of the patient.

\section{CONCLUSIONS}

During a period of up to 10 (mean 6.2) years following normal MPS, rates of ACD (1.9\%/year) and hard cardiac events $(0.8 \%$ /year) were low, but higher than in the general population. Event rates varied with gender, age, and known CAD. Of particular interest, patients with known CAD, but no prior revascularization, constituted a subset with the highest and fastest growing mortality risk, reaching $6 \%$ in 4 years. Another novel finding was that events occurred relatively late, suggesting a general warranty period of 5 years, but somewhat shorter in risk groups.

\section{Acknowledgments}

This study was part of a PhD project. The primary author received a PhD scholarship from The PhD Research Fund at Odense University Hospital, Odense, Denmark.

\section{References}

1. Bourque JM, Beller GA. Stress myocardial perfusion imaging for assessing prognosis: an update. JACC Cardiovasc Imaging 2011:4:1305-19.

2. Mowatt G, Brazzelli M, Gemmell H, Hillis GS, Metcalfe M, Vale L. Systematic review of the prognostic effectiveness of SPECT myocardial perfusion scintigraphy in patients with suspected or known coronary artery disease and following myocardial infarction. Nucl Med Commun 2005;26:217-29.

3. Schinkel AF, Elhendy A, van Domburg RT, Bax JJ, Valkema R, Roelandt JR, et al. Long-term prognostic value of dobutamine stress 99mTc-sestamibi SPECT: Single-center experience with 8-year follow-up. Radiology 2002;225:701-6.

4. Metz LD, Beattie M, Hom R, Redberg RF, Grady D, Fleischmann KE. The prognostic value of normal exercise myocardial perfusion imaging and exercise echocardiography: A meta-analysis. J Am Coll Cardiol 2007;49:227-37.

5. Yao SS, Rozanski A. Principal uses of myocardial perfusion scintigraphy in the management of patients with known or suspected coronary artery disease. Prog Cardiovasc Dis 2001;43:281-302.

6. Soman P, Parsons A, Lahiri N, Lahiri A. The prognostic value of a normal Tc-99m sestamibi SPECT study in suspected coronary artery disease. J Nucl Cardiol 1999;6:252-6.

7. Navare SM, Mather JF, Shaw LJ, Fowler MS, Heller GV. Comparison of risk stratification with pharmacologic and exercise stress myocardial perfusion imaging: A meta-analysis. J Nucl Cardiol 2004;11:551-61.

8. Hachamovitch R, Hayes S, Friedman JD, Cohen I, Shaw LJ, Germano $\mathrm{G}$, et al. Determinants of risk and its temporal variation in patients with normal stress myocardial perfusion scans: What is the warranty period of a normal scan? J Am Coll Cardiol 2003;41:1329-40.

9. Elhendy A, Schinkel A, Bax JJ, van Domburg RT, Poldermans D. Long-term prognosis after a normal exercise stress Tc-99m sestamibi SPECT study. J Nucl Cardiol 2003;10:261-6. 
10. Supariwala A, Uretsky S, Singh P, Memon S, Khokhar SS, WeverPinzon O, et al. Synergistic effect of coronary artery disease risk factors on long-term survival in patients with normal exercise SPECT studies. J Nucl Cardiol 2011;18:207-14.

11. Shaw LJ, Hage FG, Berman DS, Hachamovitch R, Iskandrian A. Prognosis in the era of comparative effectiveness research: Where is nuclear cardiology now and where should it be? J Nucl Cardiol 2012;19:1026-43.

12. Cerci MS, Cerci JJ, Cerci RJ, Pereira Neto CC, Trindade E, Delbeke $\mathrm{D}$, et al. Myocardial perfusion imaging is a strong predictor of death in women. JACC Cardiovasc Imaging 2011;4:880-8.

13. Shaw LJ, Hendel RC, Cerquiera M, Mieres JH, Alazraki N, Krawczynska E, et al. Ethnic differences in the prognostic value of stress technetium-99m tetrofosmin gated single-photon emission computed tomography myocardial perfusion imaging. J Am Coll Cardiol 2005;45:1494-504.

14. Boiten HJ, van der Sijde JN, Ruitinga PR, Valkema R, Geleijnse ML, Sijbrands EJ, et al. Long-term prognostic value of exercise technetium-99m tetrofosmin myocardial perfusion single-photon emission computed tomography. J Nucl Cardiol 2012;19:907-13.

15. Schinkel AF, Boiten HJ, van der Sijde JN, Ruitinga PR, Sijbrands EJ, Valkema R, et al 15-Year outcome after normal exercise (99m)Tcsestamibi myocardial perfusion imaging: What is the duration of low risk after a normal scan? J Nucl Cardiol 2012;19:901-6.

16. Hachamovitch R. What should we expect in a prognosis study in 2012? J Nucl Cardiol 2012;19:883-6.

17. Pedersen CB. The Danish Civil Registration System. Scand J Public Health 2011;39:22-5.

18. Thygesen LC, Daasnes C, Thaulow I, Bronnum-Hansen $\mathrm{H}$. Introduction to Danish (nationwide) registers on health and social issues: Structure, access, legislation, and archiving. Scand J Public Health 2011;39:12-6.

19. Jensen LO, Maeng M, Kaltoft A, Thayssen P, Hansen HH, Bottcher $\mathrm{M}$, et al. Stent thrombosis, myocardial infarction, and death after drug-eluting and bare-metal stent coronary interventions. J Am Coll Cardiol 2007;50:463-70.

20. Gaist D, Sorensen HT, Hallas J. The Danish prescription registries. Dan Med Bull 1997;44:445-8.

21. Berman DS, Hachamovitch R, Kiat H, Cohen I, Cabico JA, Wang $\mathrm{FP}$, et al. Incremental value of prognostic testing in patients with known or suspected ischemic heart disease: A basis for optimal utilization of exercise technetium- $99 \mathrm{~m}$ sestamibi myocardial perfusion single-photon emission computed tomography. J Am Coll Cardiol 1995;26:639-47.

22. Boyd AH, Radson D. Statistical injury incidence rate comparisons. IIE Transactions 1993;25:48-56.

23. Koehli M, Monbaron D, Prior JO, Calcagni ML, Fivaz-Arbane M, Stauffer JC, et al. SPECT myocardial perfusion imaging: Longterm prognostic value in diabetic patients with and without coronary artery disease. Nuklearmedizin 2006;45:74-81.

24. Duvall WL, Wijetunga MN, Klein TM, Razzouk L, Godbold J, Croft $\mathrm{LB}$, et al. The prognosis of a normal stress-only Tc-99m myocardial perfusion imaging study. J Nucl Cardiol 2010;17:370-7.

25. Johansen A, Hoilund-Carlsen PF, Vach W, Christensen HW, Moldrup M, Haghfelt T. Prognostic value of myocardial perfusion imaging in patients with known or suspected stable angina pectoris: Evaluation in a setting in which myocardial perfusion imaging did not influence the choice of treatment. Clin Physiol Funct Imaging 2006;26:288-95.

26. Travin MI, Duca MD, Kline GM, Herman SD, Demus DD, Heller GV. Relation of gender to physician use of test results and to the prognostic value of stress technetium $99 \mathrm{~m}$ sestamibi myocardial single-photon emission computed tomography scintigraphy. Am Heart J 1997;134:73-82.
27. Mieres JH, Rosman DR, Shaw LJ. The role of myocardial perfusion imaging in special populations: Women, diabetics, and heart failure. Semin Nucl Med 2005;35:52-61.

28. Zafrir N, Mats I, Solodky A, Kornowski R, Sulkes J, Battler A. Myocardial perfusion profile in a young population with and without known coronary artery disease: Comparison by gender. Clin Cardiol 2010;33:E39-43.

29. Berman DS, Kang X, Hayes SW, Friedman JD, Cohen I, Abidov A, et al. Adenosine myocardial perfusion single-photon emission computed tomography in women compared with men. Impact of diabetes mellitus on incremental prognostic value and effect on patient management. J Am Coll Cardiol 2003;41:1125-33.

30. Giri S, Shaw LJ, Murthy DR, Travin MI, Miller DD, Hachamovitch R, et al. Impact of diabetes on the risk stratification using stress single-photon emission computed tomography myocardial perfusion imaging in patients with symptoms suggestive of coronary artery disease. Circulation 2002;105:32-40.

31. Hachamovitch R, Kang X, Amanullah AM, Abidov A, Hayes SW, Friedman JD, et al. Prognostic implications of myocardial perfusion single-photon emission computed tomography in the elderly. Circulation 2009;120:2197-206.

32. Pavin D, Delonca J, Siegenthaler M, Doat M, Rutishauser W, Righetti A. Long-term (10 years) prognostic value of a normal thallium-201 myocardial exercise scintigraphy in patients with coronary artery disease documented by angiography. Eur Heart J 1997;18:69-77.

33. Hachamovitch R, Rozanski A, Shaw LJ, Stone GW, Thomson LE, Friedman JD, et al. Impact of ischaemia and scar on the therapeutic benefit derived from myocardial revascularization vs. medical therapy among patients undergoing stress-rest myocardial perfusion scintigraphy. Eur Heart J 2011;32:1012-24.

34. Min JK, Bell GW. The relative nature of a "normal" myocardial perfusion SPECT. J Nucl Cardiol 2010;17:983-4.

35. Nai FL, Saladini G, Cervino AR, Saladini F, Gregianin M, Razzolini R, et al. Prognostic value of myocardial perfusion scintigraphy in elderly patients with hypertension: A 10-year follow-up analysis. Eur J Nucl Med Mol Imaging 2012;39:1570-80.

36. Carryer DJ, Askew JW, Hodge DO, Miller TD, Gibbons RJ. The timing and impact of follow-up studies after normal stress singlephoton emission computed tomography sestamibi studies. Circ Cardiovasc Imaging 2010;3:520-6.

37. Kottam A, Williams KA Sr. Single-photon emission computed tomography perfusion imaging: Is using a "warranty period", warranted? Circ Cardiovasc Imaging 2010;3:505-6.

38. Zerahn B, Jensen BV, Nielsen KD, Moller S. Increased prognostic value of combined myocardial perfusion imaging and exercise electrocardiography in patients with coronary artery disease. J Nucl Cardiol 2000;7:616-22.

39. Shaw LJ, Mieres JH, Hendel RH, Boden WE, Gulati M, Veledar E, et al. Comparative effectiveness of exercise electrocardiography with or without myocardial perfusion single photon emission computed tomography in women with suspected coronary artery disease: Results from the What Is the Optimal Method for Ischemia Evaluation in Women (WOMEN) trial. Circulation 2011;124:1239-49.

40. Lauer MS, Blackstone EH, Young JB, Topol EJ. Cause of death in clinical research: Time for a reassessment? J Am Coll Cardiol 1999;34:618-20.

41. Rozanski A, Gransar H, Hayes SW, Friedman JD, Hachamovitch R, Berman DS. Comparison of long-term mortality risk following normal exercise vs adenosine myocardial perfusion SPECT. J Nucl Cardiol 2010;17:999-1008.

42. Johnson NP, Schimmel DR Jr, Dyer SP, Leonard SM, Holly TA. Survival by stress modality in patients with a normal myocardial perfusion study. Am J Cardiol 2011;107:986-9. 